\title{
PERANCANGAN E-CRM \\ PADA PT ZERO CELCIUS INDONESIA
}

\author{
Ichwan Ridwan Tandjung1; Andy Wijaya²; Darwin Kesuma³ ${ }^{3}$ Obed Bubun ${ }^{4}$ \\ 1, 2, 3, 4 Jurusan Teknik Informatika, Fakultas Ilmu Komputer, Universitas Bina Nusantara, \\ Jln. K.H. Syahdan No.9, Palmerah, Jakarta Barat 11480 \\ tandjung@binus.ac.id
}

\begin{abstract}
Purpose of this research is to analyze and design an appropriate system to help PT. Zero Celcius Indonesia in offering service to their customers, in order to keep a good relationship and communication, and also to obtain information as needed. Research methods used were library study, customers' needs analysis, designing and creating of e-CRM system, programming, and system testing as suggested. Result got from the survey to company was that the current CRM system was only run by limited company staffs. Whereas the clients owned by company were considered quite many. Therefore, a CRM based on web or also known as e-CRM was being created. So, the conclusion is that because of e-CRM, a better service to the customers can be given more focus and a relationship between company and customers can be closer; not only as market subjects, but as colleagues.
\end{abstract}

Keywords: analysis, design, e-CRM

\begin{abstract}
ABSTRAK
Tujuan penelitian adalah untuk menganalisis dan merancang sistem yang tepat untuk membantu PT. Zero Celcius Indonesia dalam memberikan pelayanan kepada kliennya agar hubungan dan komunikasi tetap terjaga, serta bisa memperoleh informasi sesuai kebutuhan. Metode penelitian yang digunakan yaitu studi pustaka, analisis kebutuhan pengguna, perancangan dan pembuatan sistem e-CRM, pemrograman, serta pengujian sistem yang diusulkan. Adapun hasil yang didapat dari survei ke perusahaan adalah CRM yang sedang berjalan hanya dijalankan oleh staf perusahaan yang terbatas. Sedangkan klien yang dimiliki perusahaan tergolong cukup banyak. Oleh karena itu, dirancanglah CRM berbasis web atau biasa disebut dengan e-CRM. Jadi, kesimpulannya adalah dengan adanya e-CRM, pelayanan yang diberikan kepada klien akan semakin terfokus, serta hubungan antara klien dengan perusahaan bisa lebih dekat; bukan hanya sebagai pelaku pasar, tetapi sebagai teman kerja.
\end{abstract}

Kata kunci: analisis, perancangan, e-CRM

\section{PENDAHULUAN}

Perkembangan teknologi yang semakin maju dan persaingan di dunia bisnis pada zaman sekarang sudah semakin ketat. Hal ini dapat dilihat dari perusahaan baru yang bermunculan menghasilkan produk yang hampir atau bahkan sama dengan perusahaan yang sudah besar atau mapan. Selain itu, sekarang mudah untuk mendapatkan dan membuat suatu produk dengan fitur dan kualitas yang serupa dengan yang sudah ada di pasaran. Sebagai contoh, sekarang sudah banyak beredar produk-produk buatan negara Cina dengan fitur dan kualitas yang serupa dengan produk-produk asli dari negara lain, tetapi dapat dijual dengan harga yang jauh lebih murah.

Oleh karena masalah tersebut, perbedaan teknologi antara perusahaan besar dengan perusahaan yang baru berkembang menjadi sangat kecil. Kalau perusahaan besar masih mengandalkan produk (product focus), pasti mereka akan tersusul oleh perusahaan baru. Maka dari itu, perusahaan besar saat ini sudah tidak 
hanya fokus terhadap produk, tetapi juga pelanggannya (customer). Keterfokusan terhadap customer perlu dilakukan oleh perusahaan karena untuk mendapatkan customer lebih susah dan butuh biaya lebih besar daripada menjaga customer yang sudah ada. Sementara itu, customer juga memilki kecenderungan untuk tidak hanya beli barang, dapat barang, lalu selesai. Mereka juga ingin lebih, yaitu beli barang, memilih servis, dapat barang dan servis, lalu beli lagi, sehingga pelanggan menginginkan hubungan 2 arah dengan perusahaan yang mampu memberikan pelayanan tambahan tanpa terasa 'mahal'.

Karena pentingnya hubungan perusahaan dengan customer, maka diperlukan suatu sistem untuk mempermudah komunikasi dan peningkatan pelayanan untuk memperlancar hubungan 2 arah perusahaan dengan customer. Sistem yang dimaksud adalah CRM atau Customer Relationship Management. CRM adalah salah satu bentuk aplikasi Teknologi Informasi (TI) di departemen penjualan atau pemasaran suatu perusahaan yang lebih berfokus pada pelayanan.

Dengan adanya hal-hal tersebut, maka diperlukan suatu solusi dengan memanfaatkan teknologi informasi, yaitu dengan membangun CRM yang berbasis website (e-CRM). Dipilih menggunakan website karena website bisa diakses dari mana saja dan kapan saja melalui jalur internet. Dengan begitu, perusahaan dengan klien bisa berinteraksi lebih mudah satu sama lain tanpa harus bertatap muka setiap saat.

\section{Metode Penelitian}

\section{Studi Kepustakaan}

Metode ini dilakukan dengan cara mencari pengetahuan mengenai CRM dan e-CRM, yaitu dengan membaca buku-buku yang berkaitan dengan topik permasalahan, sehingga penulis memperoleh informasi serta teori-teori yang mendukung dalam penulisan penelitian ini.

\section{Analisis Kebutuhan Pengguna}

Dalam hal ini, analisis yang dilakukan adalah mengenai survei atas sistem yang berjalan kepada pihak-pihak yang terkait, analisis terhadap temuan survei, identifikasi kebutuhan informasi, dan identifikasi persyaratan sistem. Sementara itu, hasil dari analisis digunakan sebagai masukan dalam perancangan sistem informasi yang diusulkan.

\section{Tinjauan Pustaka}

\section{Definisi CRM}

Customer Relationship Management (CRM) adalah usaha sebuah perusahaan untuk berkonsentrasi menjaga pelanggan (supaya tidak lari ke pesaing), dengan cara mengumpulkan segala bentuk interaksi pelanggan, baik itu lewat telepon, email, masukan di situs atau hasil pembicaraan dengan staf sales dan marketing (Aloysius H Danardatu, 2003: 2). CRM juga dapat diartikan sebagai suatu usaha mengelola relasi antara perusahaan dengan pelanggan, untuk peningkatan loyalitas dalam konsumsi produk-produk yang diproduksi oleh perusahaan (Oetomo, 2003: 146).

\section{Faktor Pendorong Perlunya CRM}

Beberapa faktor pendorong perlunya CRM adalah: Situasi market place yang sangat kompetitif saat ini; intelijensi, semakin tingginya tingkat inteligensi pelanggan karena mereka lebih jeli untuk melihat produk dan layanan yang ada di pasar; teknologi, teknologi yang semakin berkembang memungkinkan adanya solusi yang berbeda untuk setiap pelanggan; dan sense of business, kepuasan pelanggan tercapai dengan menyediakan apa yang dibutuhkan oleh mereka.

\section{Definisi e-CRM}


Dalam perkembangan teknologi, CRM dalam implementasinya juga telah mengalami perkembangan. Perusahaan-perusahaan juga mulai menggunakan atau memanfaatkan teknologi informasi, guna mendukung kegiatan bisnisnya. Oleh karena itu, muncullah istilah e-CRM.

Definisi e-CRM atau electronic-Customer Relationship Management adalah suatu usaha mengelola relasi antara perusahaan dengan pelanggan, dalam rangka peningkatan loyalitas pengkonsumsian produkproduk yang dipakai oleh perusahaan, dengan memanfaatkan peralatan elektronik seperti TV, radio, telepon, dan internet (Oetomo, 2003: 149).

\section{Implementasi e-CRM}

Ada beberapa pandangan mengenai pengimplementasian e-CRM. Ada yang memandang hal itu sulit dan ada yang memandangnya sederhana. Tetapi, bagaimana menciptakan relasi yang baik menimbulkan pengalaman, dan menciptakan nilai bagi pelanggan, sebenarnya hal yang paling sulit untuk dilaksanakan.

Salah satu kiat menciptakan relasi yang baik berdasarkan Oetomo et al (2003: 119) adalah dengan metode HATI (Heartsrings Are Totally Involve atau melibatkan hati sanubari secara penuh). Relasi yang muncul dari dalam hati akan dirasakan pada saat terjadi interaksi langsung maupun tidak langsung dengan pelanggan. HATI ini akan tampak pada sikap dan perilaku orang-orang dalam organisasi atau perusahaan itu dalam bentuk apapun. Jika seseorang sudah memiliki informasi, pengetahuan, rencana, strategi, hingga penjabaran panjang lebar tentang e-CRM, tetapi pada implementasinya tidak menggunakan hati, maka pelanggan akan merasakan ada yang kurang terhadap relasi itu.

Menurut Aloysius H. Danardatu (2003: 3), ada 3 faktor kunci yang diperlukan untuk mengimplementasikan sebuah strategi e-CRM, yaitu: orang-orang yang profesional (kualifikasi memadai), proses yang didesain dengan baik, dan teknologi yang memadai.

Mengerti cara menggunakan teknologi (untuk CRM) merupakan alasan mengapa 3 faktor kunci di atas diperlukan. Sebuah e-CRM yang baik diperlukan untuk: mengidentifikasi faktor-faktor kesuksesan pelanggan, menciptakan budaya dasar seorang pelanggan, mengambil langkah-langkah dasar pelanggan, mengembangkan sebuah proses end-to-end untuk melayani pelanggan-pelanggan, merekomendasikan pertanyaan-pertanyaan apa untuk bertanya untuk membantu seorang pelanggan memecahkan suatu masalah, merekomendasikan apa yang dikatakan seorang pelanggan dengan sebuah saran mengenai pembelian, serta membawa semua aspek dari penjualan ke pelanggan dan prospek-prospek.

Sebelum melakukan implementasi, perspektif para pelaku e-CRM perlu dipahami karena perspektif terhadap e-CRM di suatu perusahaan dengan perusahaan lain bisa berbeda.

\section{PEMBAHASAN}

PT Zero Celcius Indonesia adalah perusahaan yang bergerak dalam bidang web, mencakup pembuatan web, web hosting, dan web marketing. PT Zero Celcius Indonesia beralamatkan di Gedung Graha Hijau, Jln. Sungai Gerong No.8, Jakarta 10230. Melihat dunia web yang sangat luas, maka PT Zero Celcius Indonesia memulai pada desain web sederhana. Kemudian makin lama berkembang hingga pembuatan web portal, e-learning, dan menerima web hosting, serta web marketing. Dalam usianya yang belum mencapai 2 tahun, PT Zero Celcius Indonesia telah menangani banyak klien; mulai dari web individu, sampai ke web korporat.

PT Zero Celcius Indonesia memiliki visi untuk memajukan dunia website di Indonesia, yang saat ini masih terbilang low in quality, sekaligus untuk menjadi web studio yang melayani web solution service dengan lingkungan kerja yang fleksibel dan menyenangkan. Sedangkan untuk menjadikan setiap website yang dibuat menjadi sebuah website yang indah, dinamis, dan bermanfaat bagi bisnis klien PT Zero Celcius Indonesia merupakan misi utama dari PT Zero Celcius Indonesia. Berikut ini adalah moto dari PT Zero Celcius Indonesia, "Kepuasan klien adalah kepuasan kami”. Proses bisnis dari perusahaan ini dapat dilihat pada Gambar 1. 


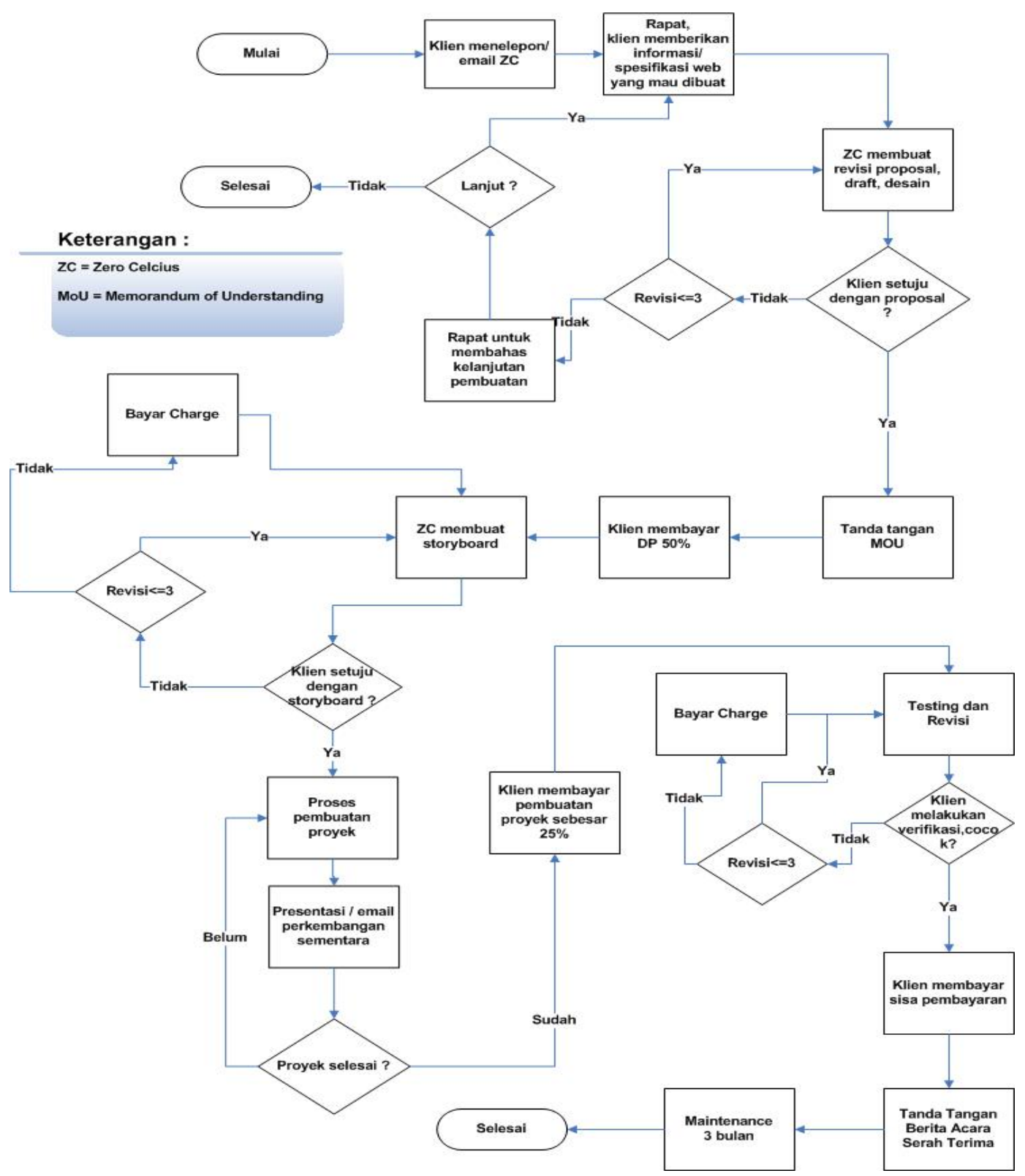

Gambar 1 Proses Bisnis PT Zero Celcius Indonesia

\section{Permasalahan yang Dihadapi}

Dari hasil analisis SWOT dan hasil wawancara yang telah kami lakukan dengan Direktur PT Zero Celcius, Bapak Jethro Jiang, serta kuisioner yang kami berikan kepada klien-klien PT Zero Celcius, didapat kesimpulan seperti: kurangnya fasilitas untuk menjaga relasi perusahaan dengan klien; sulitnya menangani semua klien yang terbilang sudah cukup banyak; kurangnya staf yang ada di perusahaan, terutama pada bagian pelayanan customer atau klien; serta struktur manajemen yang masih lemah.

\section{Use Case Diagram}

e-CRM yang diusulkan pada PT Zero Celcius Indonesia dapat dilihat dari sub bab pada Gambar 2 dan 3. 


\section{Sequence Diagram}

Sequence diagram terbagi menjadi dua, yaitu sequence diagram sistem proyek (Gambar 4) dan sequence diagram sistem file (Gambar 5).

\section{Statechart Diagram}

Statechart diagram terbagi menjadi dua, yaitu statechart diagram untuk class admin (Gambar 6) dan statechart diagram untuk class klien (Gambar 7).

\section{Entity Relationship Diagram}

Gambar 8 merupakan entity relationship diagram.

\section{Perancangan Layar}

Gambar 9 merupakan contoh rancangan layar progress report, sedangkan contoh rancangan layar client: manage client terdapat pada Gambar 10.

\section{Implementasi}

Gambar 11 merupakan tampilan layar Manage Client, sedangkan Tampilan Layar Progress Report (Tampilan Layar Klien) digambarkan pada Gambar 12.

\section{PENUTUP}

\section{Kesimpulan}

Kesimpulan yang didapat adalah sebagai berikut. Pertama, website e-CRM yang dikembangkan bagi PT Zero Celcius Indonesia dapat digunakan bagi kepentingan PT Zero Celcius Indonesia, dalam kegiatan bisnisnya. Kedua, website e-CRM ini mendukung kegiatan PT Zero Celcius Indonesia dengan kemudahan dalam berinteraksi dengan klien maupun customer. Ketiga, website ini tidak mendukung untuk dilakukannya transaksi pembayaran secara online.

\section{Saran}

Saran-saran yang diberikan di dalam penelitian ini adalah penambahan fasilitas sebaiknya dilakukan di masa mendatang, untuk memenuhi kebutuhan perusahaan dan klien PT Zero Celcius Indonesia yang semakin banyak; serta diharapkan agar sering melakukan pemantauan melalui halaman administrasi agar dapat memberikan respon yang cepat terhadap pengunjung dan terutama klien. 


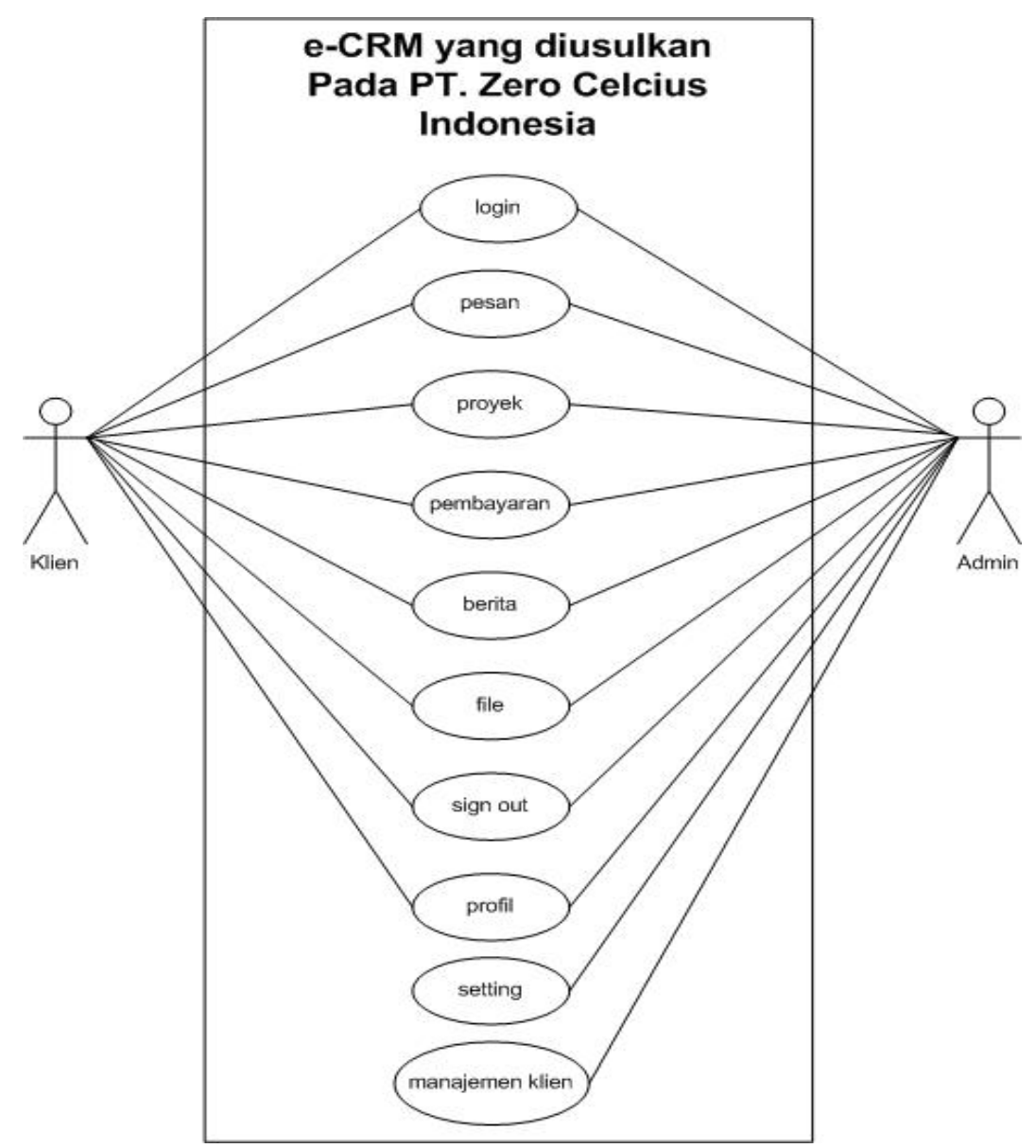

Gambar 2 Use Case Diagram e-CRM Secara Keseluruhan Class Diagram 


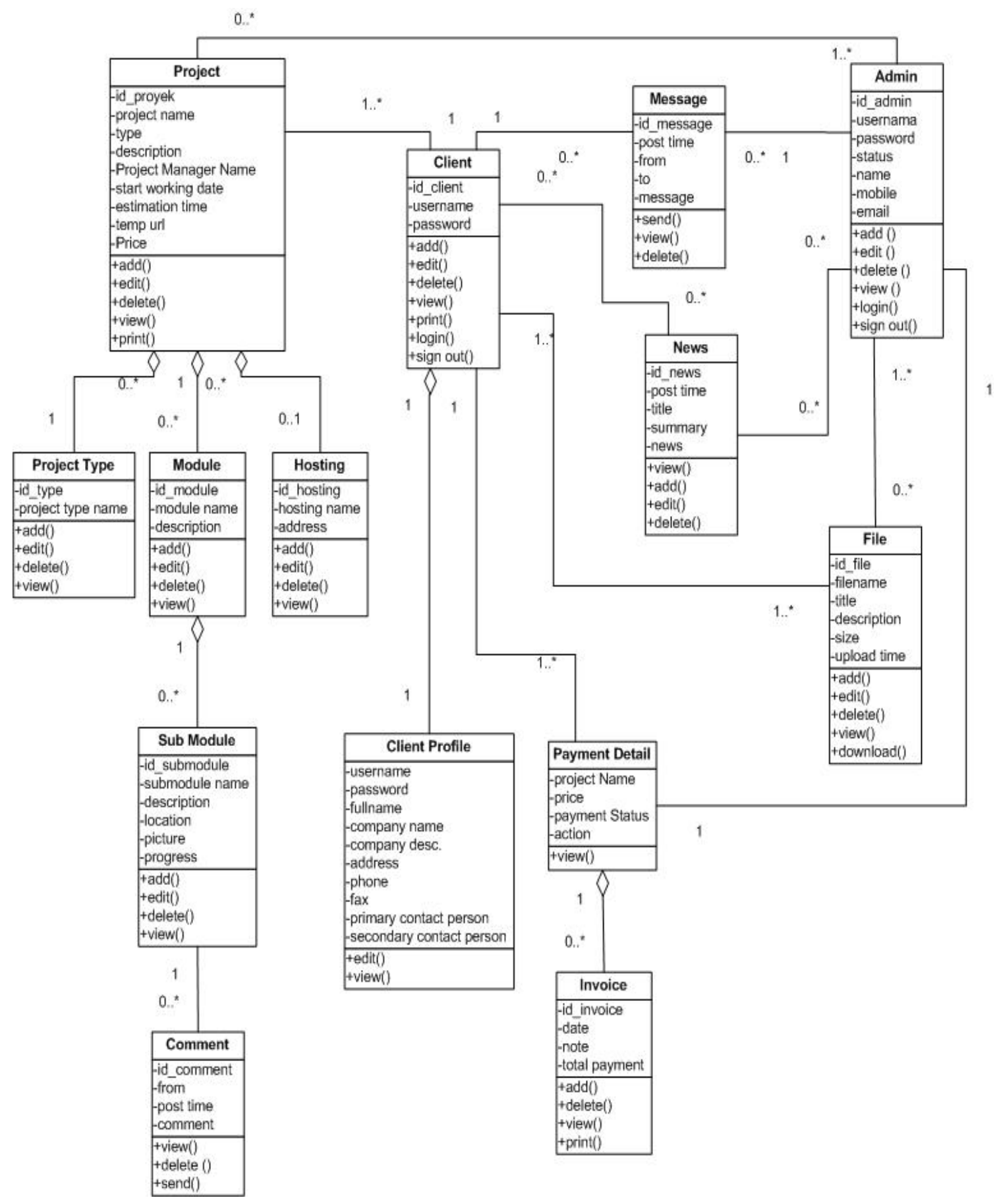

Gambar 5 Class Diagram dari Sistem e-CRM yang Diusulkan 


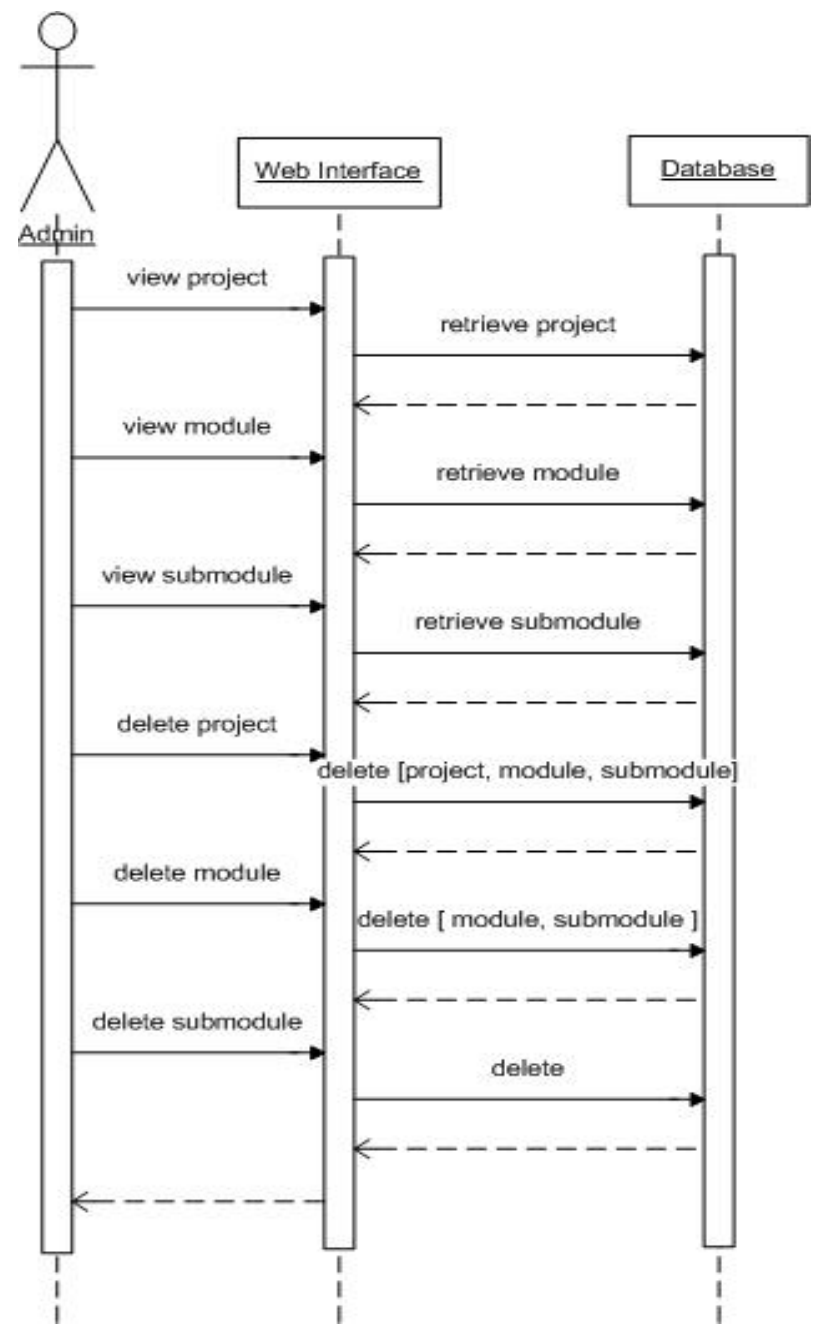

Gambar 3 Sequence Diagram Sistem Proyek 


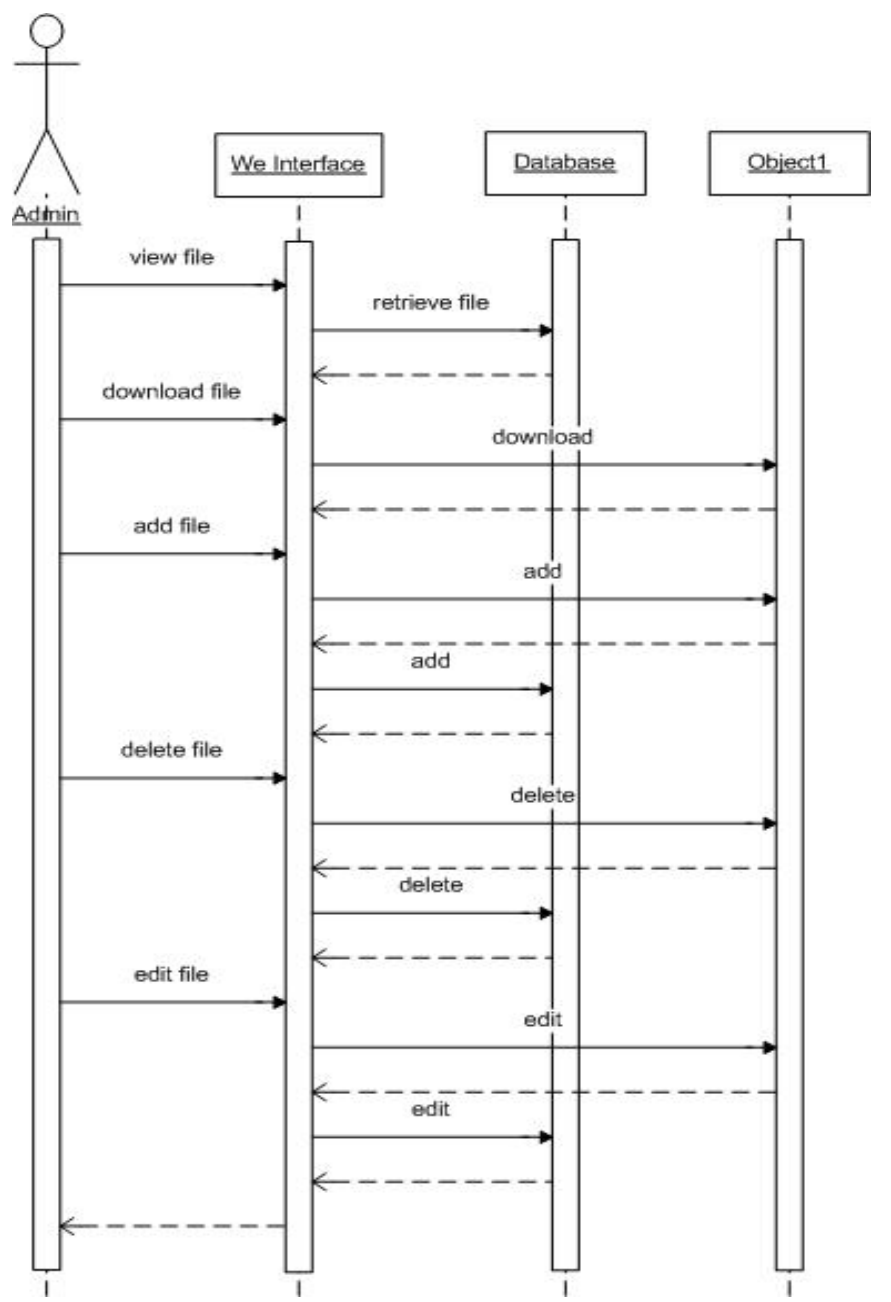

Gambar 4 Sequence Diagram Sistem File

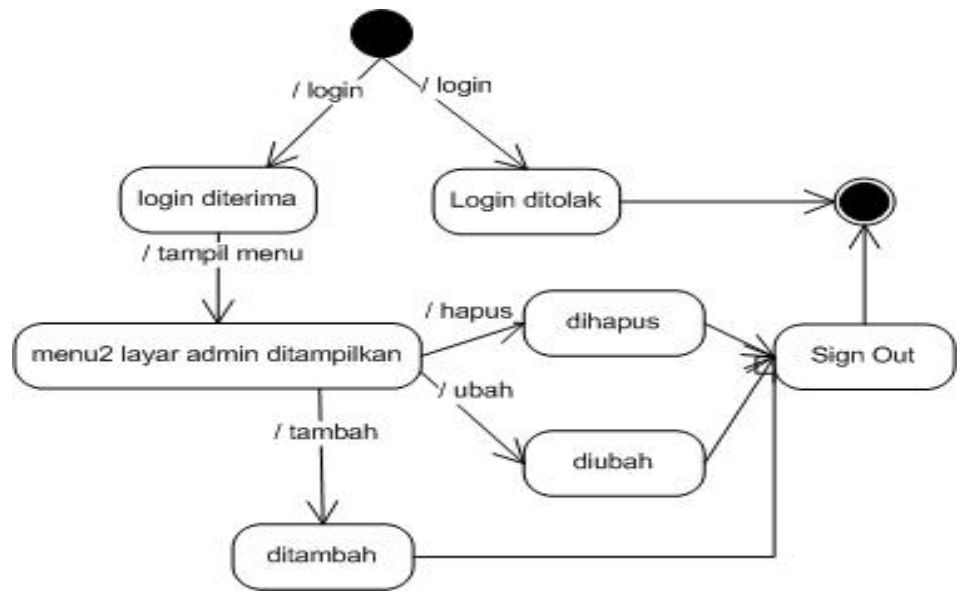

Gambar 6 Statechart Diagram untuk Class Admin 


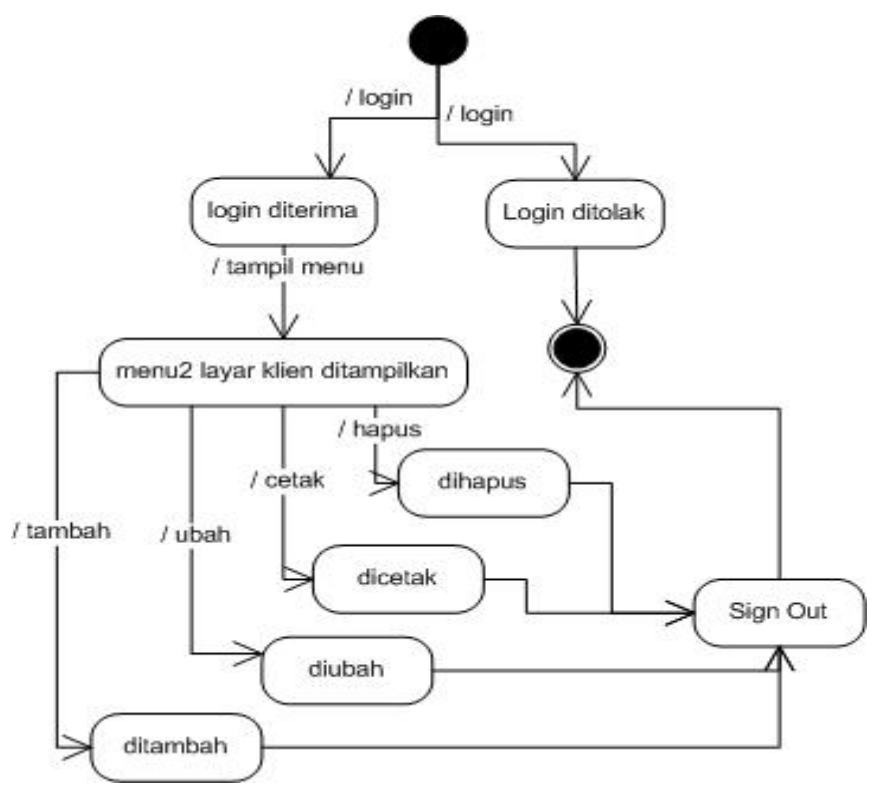

Gambar 7 Statechart Diagram dari Class Klien 


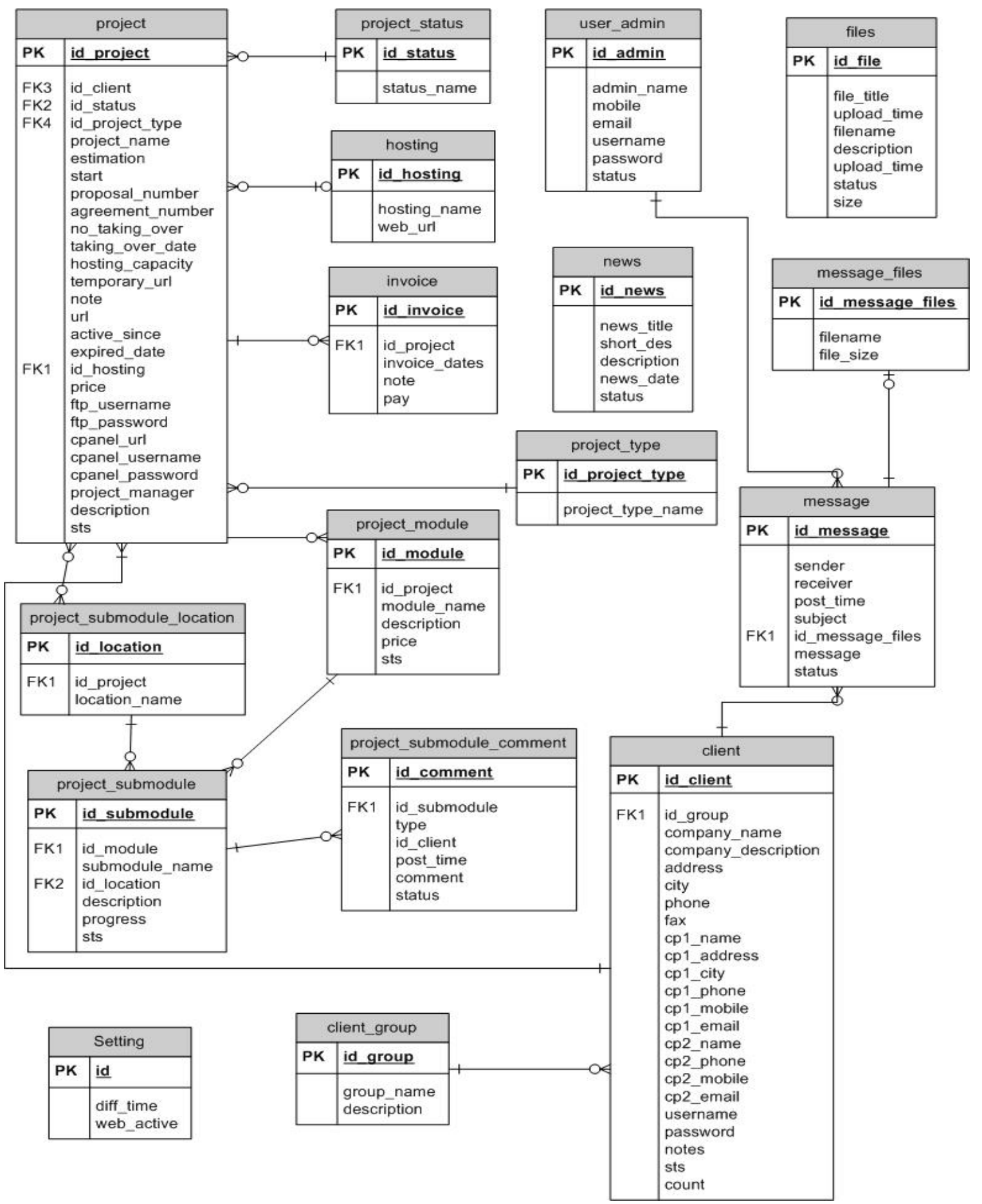

Gambar 8 Entity Relationship Diagram 


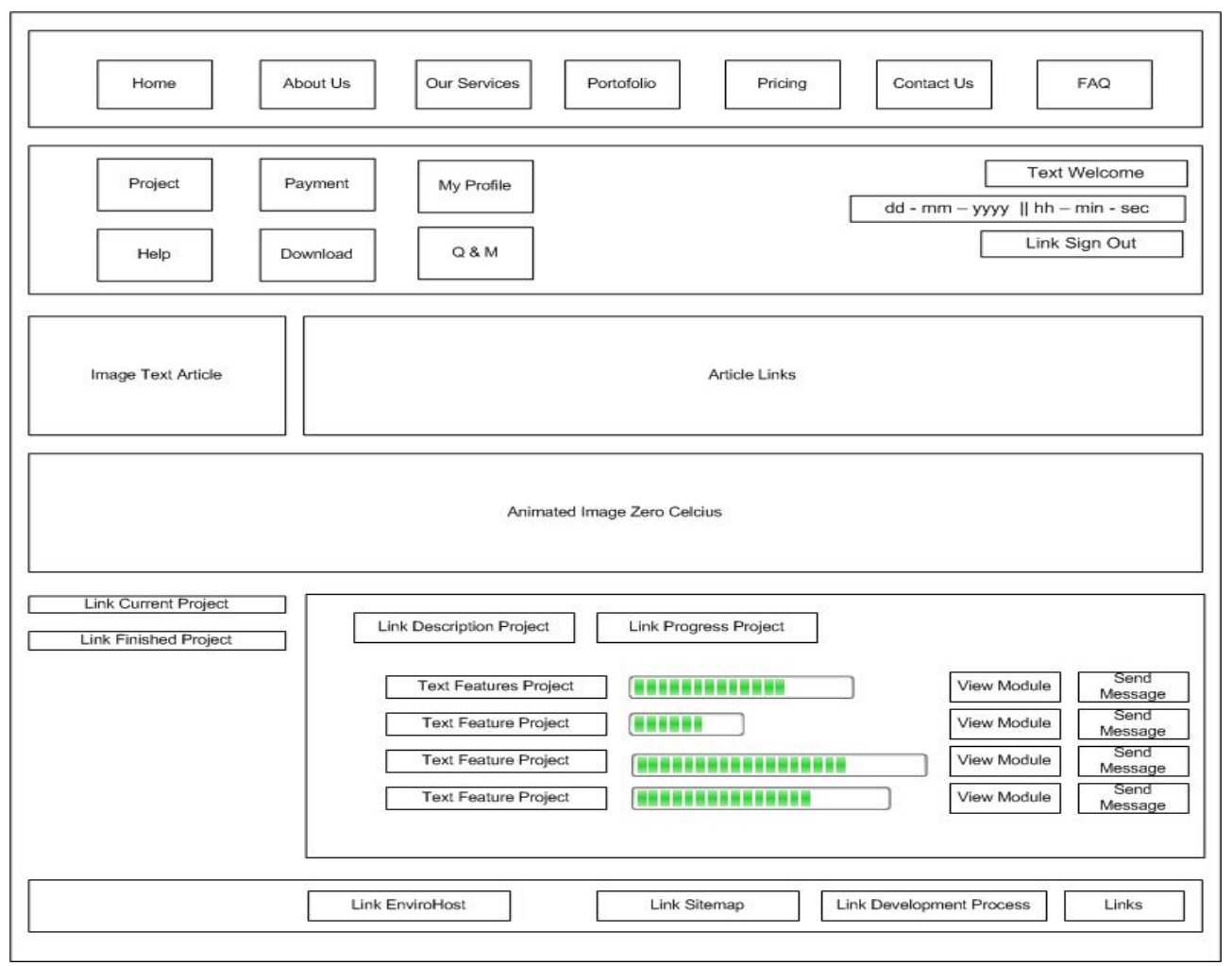

Gambar 9 Rancangan Layar Progress Report

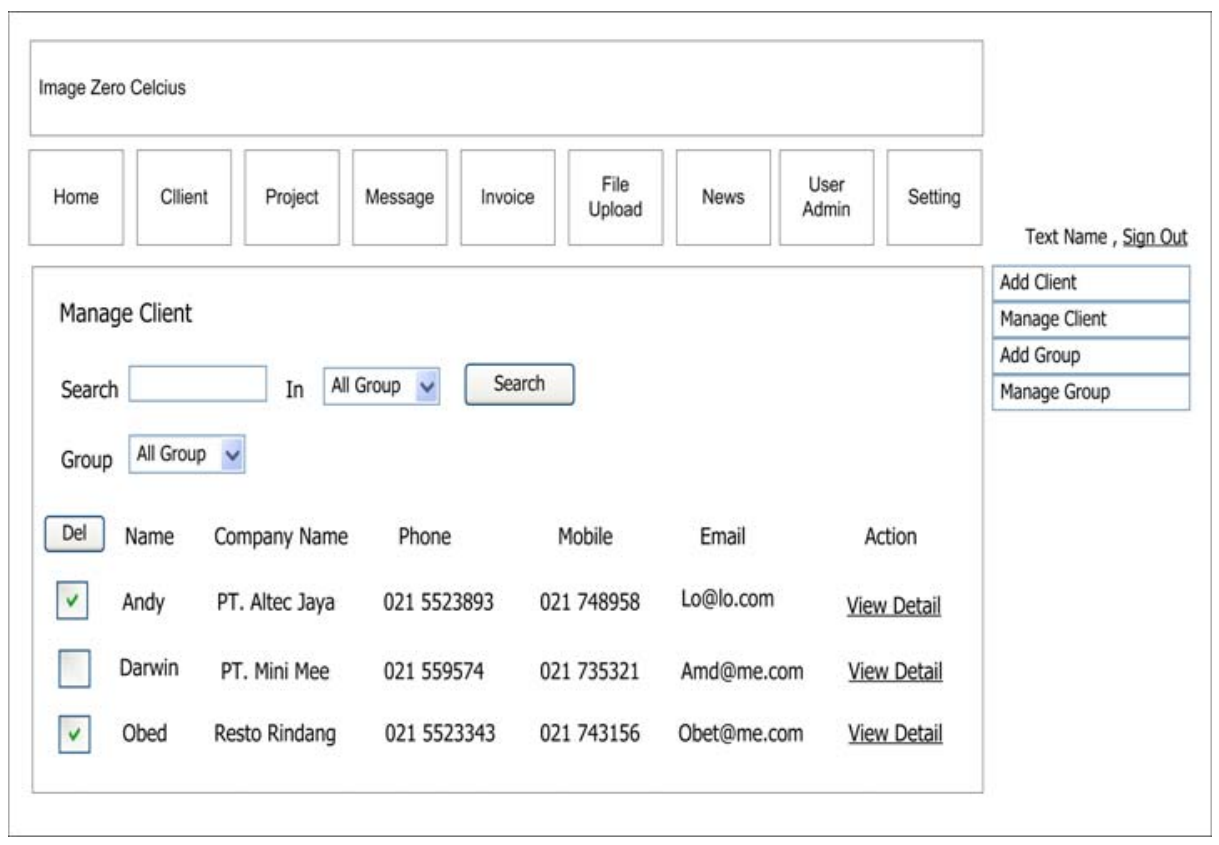

Gambar 10 Rancangan Layar Client: Manage Client 


\section{ZC! zerocelcius}

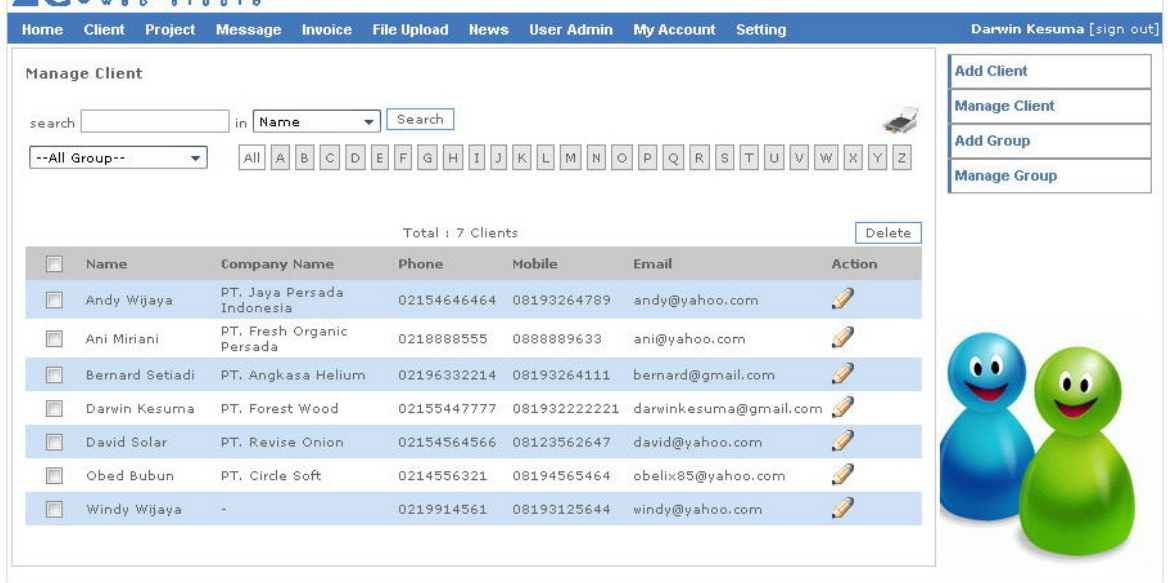

Gambar 11 Tampilan Layar Manage Client

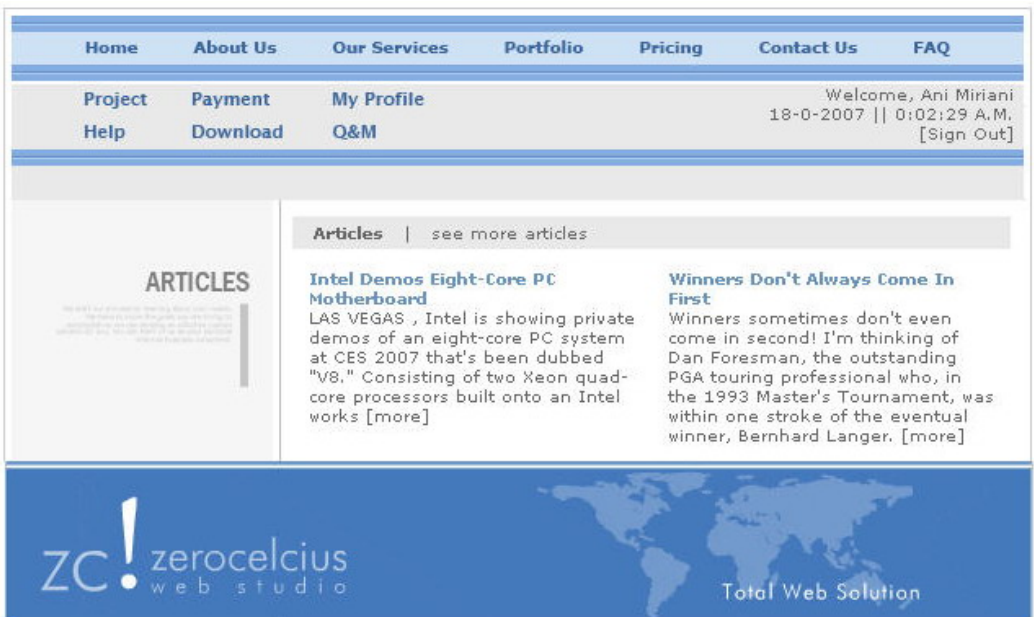

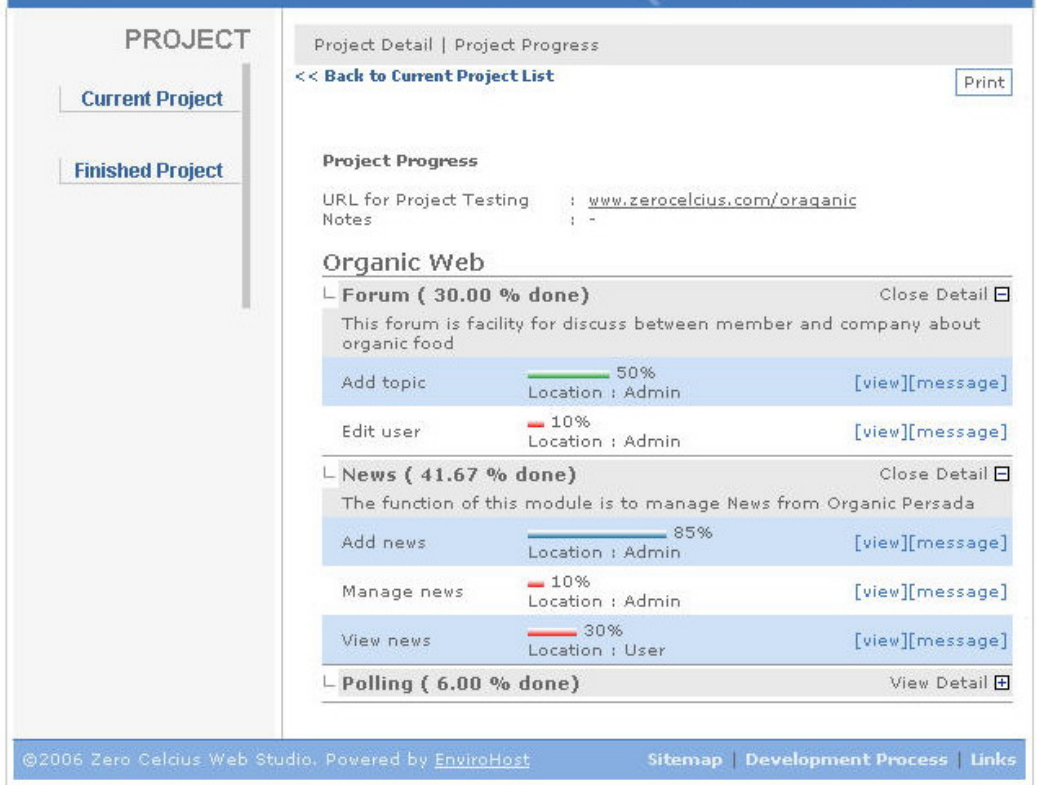

Gambar 12 Tampilan Layar Progress Report 


\section{DAFTAR PUSTAKA}

Amor, D. (2002). The e-Business Revolution. Hewlett-Packard Books, Upper Saddle River, Edisi kedua.

Anchour, M., dkk. (2006). PHP Manual. PHP Documentation Group.

Anonim.(2006). Frequently Asked Questions. http://www.apache.org/foundation/faq.html\# name.

Anonim.(2006). MySQL 5.1 Reference Manual. MySQL AB.

Anonim.(2006). Online. http://en.wikipedia.org/wiki/Online.

Connolly, T., dan Begg, C. (2002). Database System A Practical Appproach to Design, Implementation, and Management. $3^{\text {rd }}$ Edition. Edinburg: Addison-Wesley.

Danardatu, A. H. (2003). Pengenalan Customer Relationship Management (CRM). http://IlmuKomputer.com.

Dharwiyanti, S., dan Wahono, R. S. (2003). Pengantar Unified Modelling Language (UML). http://IlmuKomputer.com.

Dyche, J. (2002). The CRM HandBook - A Business Guide to Customer Relationship Management. Edinburg, England: Addison-Wesley.

Kalakota, R., dan M. Robinson. (2001). e-Business 2.0: Roadmap for Success. Edisi kedua. Canada: Addison-Wesley.

Lethbridge, T. C., dan Laganière, L. (2001). Object-Oriented Software Engineering. Maidenhead: McGrawHill.

McDonald, H. B., Malcolm, Rogers, Beth, Woodburn, Diana. (2000). Key Customers: How to Manage Them Profitably. The Chartered Institute of Marketing. Canada: Elsevier.

Oetomo, B., J. Simandjuntak, dan A. Sukoco. (2003). i-CRM Membina Relasi dengan Pelanggan.Com. Yogyakarta: Andi.

Pressman, R. S. (2001). Software Engineering. Edisi kelima. New York: McGraw-Hill.

Philippus, Erwin. (2004). 12 Game dengan JavaScript. Yogyakarta: Andi.

Rickyanto, Isak. (2002). Desain Web dengan Dreamweaver MX. Jakarta: Elek Media Komputindo.

Schmuller, J. (1999). Sams Teach Yourself UML in 24 Hours. Indiana, USA: Sams.

Setiawan, Andi. (2004) . Mudah, Tepat, Singkat Pemrograman HTML. Bandung: Yrama Widya.

Seybold, Patricia. (2002). An Executive Guide to CRM. PS Group. Boston: MA.

Shneiderman, B. (1998). Designing the User Interface Strategies for Effective Human-Computer Interaction. Edinburg, England: Addison-Wesley.

Tim Penyusun Kamus Pusat Pembinaan dan Pengembangan Bahasa. (1993). Buku Besar Bahasa Indonesia. Jakarta: Balai Pustaka.

Trinkle, Dennis A., dan Scott A Merriman. (2002). The History Highway 3.0: A Guide to Internet Resources. Edisi ketiga. Boston: M. E. Sharpe.

Whitten, J. L., Bently, L. D., dan Dittman, K. C. (2004). Systems Analysis and Design Methods. New York: McGraw-Hill.

Zingale, A., dan Mathias Arndt. (2001). New Economy Emotion: Engaging Customer Passion with e-CRM. Toronto: John Wiley and Sons Inc. 